\title{
Use of Conventional Fishery Models to Assess Entrainment and Impingement of Three Lake Michigan Fish Species ${ }^{1}$
}

\author{
A. L. JENSEN \\ School of Natural Resources, University of Michigan, Ann Arbor, Michigan 48109 \\ S. A. Spigarelli and M. M. Thommes \\ Ecological Sciences Section, Radiological and Environmental Research Division \\ Argonne National Laborator, Argonne, Illinois 60439
}

\begin{abstract}
Two conventional fishery stock assessment models, the surplus-production model and the dynamic-pool model, were applied to assess the impacts of water withdrawals by electricitygenerating plants, industries, and municipalities on the standing stocks and yields of alewife Alosa pseudoharengus, rainbow smelt Osmerus mordax, and yellow perch Perca flavescens in Lake Michigan. Impingement and entrainment estimates were based on data collected at 15 power plants. The surplus-production model was fitted to the three populations with catch and effort data from the commercial fisheries. Dynamic-pool model parameters were estimated from published data. The numbers entrained and impinged are large, but the proportions of the standing stocks impinged and the proportions of the eggs and larvae entrained are small. The reductions in biomass of the stocks and in maximum sustainable yields are larger than the proportions impinged. The reductions in biomass, based on 1975 data and an assumed full water withdrawal, are $2.86 \%$ for alewife, $0.76 \%$ for rainbow smelt, and $0.28 \%$ for yellow perch. Fishery models are an economical means of impact assessment in situations where catch and effort data are available for estimation of model parameters.
\end{abstract}

The combined capacity for water withdrawal by all power-plant, industrial, and municipal water intakes on Lake Michigan exceeds $4.8 \times$ $10^{10} \mathrm{~m}^{3}$ per year. Although many intakes are not operated continuously or at full capacity, the volume withdrawn is large. Entrainment of fish eggs and larvae in water passing through intake screens and impingement of larger fishes on intake screens during water withdrawal has caused concern. In this study, two conventional stock assessment models were applied to estimate fish abundances and to simulate the impact on standing stocks and yields of water withdrawals from Lake Michigan.

To estimate the effect of entrainment and impingement, the sizes of the populations must be known. Direct estimates of abundance are difficult and costly for large populations, so abundances were estimated with models. Two different models were applied to give two nearly independent estimates. The models are based on different assumptions and two differ-

\footnotetext{
${ }^{1}$ Work performed under the auspices of the
} United States Environmental Protection Agency. ent sets of data are used for nearly all parameter estimates.

The most frequently impinged and entrained species in Lake Michigan are alewife Alosa pseudoharengus, yellow perch Perca flavescens, and rainbow smelt Osmerus mordax, so the impact on these species was assessed. All three species support small commercial fisheries. Yellow perch and rainbow smelt are also important to sport fishermen. Alewife and rainbow smelt are important forage fish for lake trout Salvelinus namaycush and other stocked salmonids.

\section{Acquisition and Development of Data}

Data were obtained from environmental-impact studies at 15 power plants located on Lake Michigan (Fig. 1) and from federal and state resource agencies. Most plants were sampled in 1975. The sampling schedules and methods varied among plants; methods are summarized by Spigarelli et al. (1981). Power-plant data sets that spanned less than 1 year were expanded to a full year by linear extrapolation from the last data entry to zero at the end of the year or from zero to the first data entry for the year. 


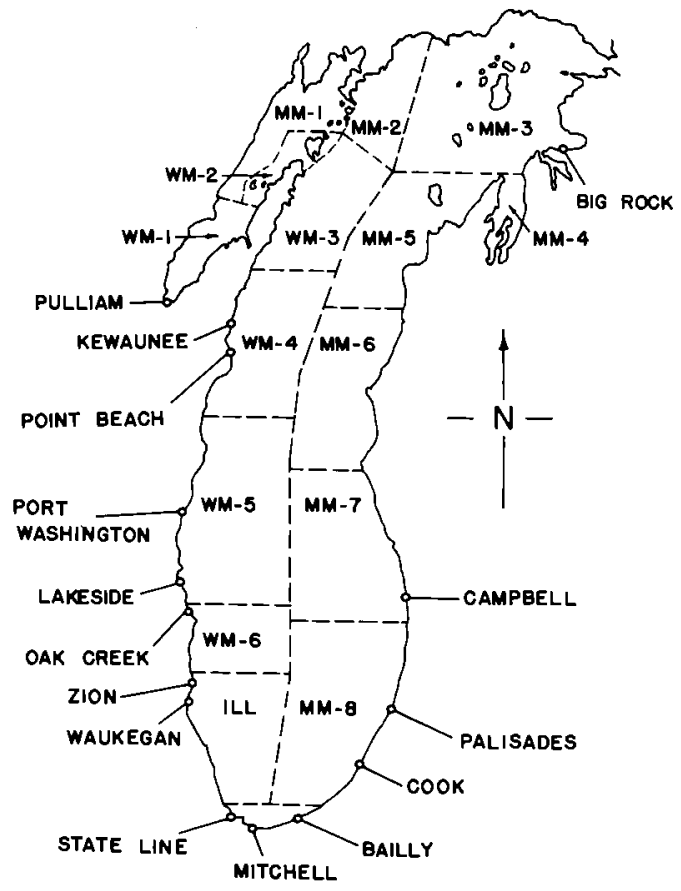

FIGURE 1.-Locations of sampled power plants on Lake Michigan. Symbols and broken lines define fishery statistical districts.

Daily average flow rates were obtained for each plant, and daily impingement and entrainment estimates were calculated for each plant with a weighted linear interpolation. Daily values were

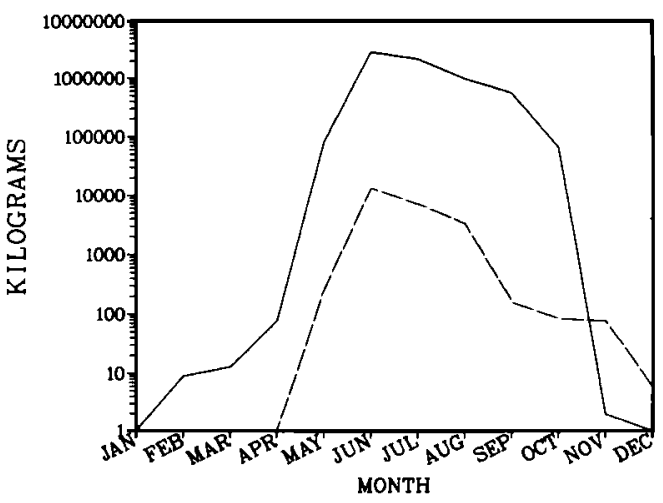

FIguRE 2.-Commercial alewife catch from Lake Michigan district WM-1 (solid line) and observed alewife impingement (dashed line) at Pulliam Power Plant during 1975.

summed by month and year for each plant. For each of the three species, biomass impinged and number of eggs and larvae entrained were calculated.

Model calculations assumed that power plants withdrew water at their full design flows, and that all impinged and entrained fish and fish eggs died. Thus, the estimates and simulation results presented are worst-case assessments.

The annual alewife impingement at the sampled power plants was estimated as $9.17 \times 10^{5}$ $\mathrm{kg}$ (Table 1). Impingement was strongly depen-

TABLE 1.-Observed impingement of alewives, rainbow smelt, and yellow perch at 15 Lake Michigan power plants in 1975, and actual and maximum potential water withdrawal. Estimated annual totals are extrapolations to the full year.

\begin{tabular}{|c|c|c|c|c|c|}
\hline Power plant & $\begin{array}{l}\text { Total flow } \\
\text { (m³/year) }\end{array}$ & $\begin{array}{c}\text { Maximum flow } \\
\left(\mathrm{m}^{3} / \text { year }\right)\end{array}$ & $\begin{array}{l}\text { Alewife } \\
\text { (kg) }\end{array}$ & $\begin{array}{c}\text { Rainbow smelt } \\
(\mathrm{kg})\end{array}$ & $\begin{array}{l}\text { Yellow perch } \\
(\mathrm{kg})\end{array}$ \\
\hline Zion & $2.04 \times 10^{9}$ & $3.48 \times 10^{9}$ & $6.80 \times 10^{5}$ & $2.48 \times 10^{3}$ & $6.90 \times 10^{1}$ \\
\hline Cook & $1.32 \times 10^{9}$ & $3.27 \times 10^{9}$ & $5.11 \times 10^{3}$ & $5.10 \times 10^{1}$ & $3.97 \times 10^{2}$ \\
\hline Bailly & $4.71 \times 10^{\mathrm{B}}$ & $6.70 \times 10^{8}$ & $4.52 \times 10^{3}$ & $1.70 \times 10^{1}$ & $4.40 \times 10^{1}$ \\
\hline Pulliam & $3.34 \times 10^{8}$ & $7.75 \times 10^{8}$ & $2.46 \times 10^{4}$ & $2.73 \times 10^{2}$ & $2.14 \times 10^{3}$ \\
\hline Kewaunee & $6.70 \times 10^{8}$ & $8.22 \times 10^{8}$ & $4.84 \times 10^{3}$ & $4.75 \times 10^{2}$ & $4.00 \times 10^{1}$ \\
\hline Point Beach & $1.21 \times 10^{\theta}$ & $1.53 \times 10^{9}$ & $3.74 \times 10^{4}$ & $1.26 \times 10^{3}$ & $3.90 \times 10^{1}$ \\
\hline Port Washington & $5.74 \times 10^{8}$ & $1.09 \times 10^{9}$ & $6.11 \times 10^{4}$ & $8.95 \times 10^{2}$ & $2.30 \times 10^{1}$ \\
\hline Lakeside & $2.64 \times 10^{8}$ & $8.73 \times 10^{8}$ & $1.40 \times 10^{3}$ & $2.00 \times 10^{0}$ & $3.00 \times 10^{0}$ \\
\hline Oak Creek & $1.64 \times 10^{9}$ & $2.45 \times 10^{9}$ & $3.29 \times 10^{4}$ & $3.76 \times 10^{3}$ & $1.06 \times 10^{2}$ \\
\hline Waukegan & $9.32 \times 10^{8}$ & $1.43 \times 10^{9}$ & $2.80 \times 10^{4}$ & $3.77 \times 10^{2}$ & $3.80 \times 10^{1}$ \\
\hline Stateline & $1.02 \times 10^{9}$ & $1.65 \times 10^{9}$ & $2.19 \times 10^{4}$ & $2.30 \times 10^{1}$ & $8.20 \times 10^{1}$ \\
\hline Mitchell & $5.11 \times 10^{8}$ & $8.23 \times 10^{8}$ & $3.68 \times 10^{3}$ & $4.00 \times 10^{0}$ & $4.60 \times 10^{1}$ \\
\hline Campbell & $4.17 \times 10^{8}$ & $5.97 \times 10^{8}$ & $1.10 \times 10^{3}$ & $1.07 \times 10^{3}$ & $7.14 \times 10^{0}$ \\
\hline Palisades & $1.22 \times 10^{8}$ & $1.19 \times 10^{8}$ & $1.22 \times 10^{1}$ & $2.27 \times 10^{-1}$ & $1.13 \times 10^{-1}$ \\
\hline Big Rock & $8.20 \times 10^{7}$ & $9.55 \times 10^{7}$ & $3.51 \times 10^{0}$ & $2.38 \times 10^{0}$ & $2.04 \times 10^{0}$ \\
\hline Total observed & $1.16 \times 10^{10}$ & & $9.07 \times 10^{5}$ & $9.63 \times 10^{3}$ & $3.03 \times 10^{3}$ \\
\hline Estimated annual total & & $1.97 \times 10^{10}$ & $9.17 \times 10^{5}$ & $9.77 \times 10^{3}$ & $3.11 \times 10^{3}$ \\
\hline
\end{tabular}


TABLE 2.-Estimated total numbers of alewife, rainbow smelt, and yellow perch eggs and larvae entrained during 1975 sampling period at 15 sampled power plants on Lake Michigan; estimated annual totals are extrapolations to the full year. N/A means not available.

\begin{tabular}{|c|c|c|c|c|c|c|c|}
\hline \multirow[b]{2}{*}{ Power plant } & \multirow{2}{*}{$\begin{array}{l}\text { Total flow } \\
\qquad\left(\mathrm{m}^{3}\right)\end{array}$} & \multicolumn{2}{|c|}{ Alewife } & \multicolumn{2}{|c|}{ Raibow smelt } & \multicolumn{2}{|c|}{ Yellow perch } \\
\hline & & Eggs & Larvae & Eggs & Larvae & Eggs & Larvae \\
\hline Zion & $5.52 \times 10^{\mathrm{s}}$ & $4.73 \times 10^{8}$ & $4.39 \times 10^{6}$ & $4.47 \times 10^{7}$ & $3.13 \times 10^{8}$ & N/A & N/A \\
\hline Cook & $1.30 \times 10^{9}$ & $6.21 \times 10^{8}$ & $6.51 \times 10^{7}$ & $7.86 \times 10^{6}$ & $2.91 \times 10^{5}$ & $4.05 \times 10^{6}$ & $6.37 \times 10^{4}$ \\
\hline Bailly & $6.16 \times 10^{8}$ & $3.86 \times 10^{8}$ & $3.80 \times 10^{7}$ & $4.14 \times 10^{6}$ & $2.87 \times 10^{5}$ & $1.24 \times 10^{4}$ & $1.42 \times 10^{4}$ \\
\hline Pulliam & $1.52 \times 10^{8}$ & $2.93 \times 10^{8}$ & $4.84 \times 10^{4}$ & $6.87 \times 10^{5}$ & $2.52 \times 10^{4}$ & $2.32 \times 10^{6}$ & $5.17 \times 10^{5}$ \\
\hline Kewaunee & $5.33 \times 10^{\mathrm{B}}$ & $4.71 \times 10^{7}$ & $6.03 \times 10^{5}$ & $9.85 \times 10^{5}$ & $9.45 \times 10^{6}$ & N/A & N/A \\
\hline Point Beach & $8.08 \times 10^{8}$ & $4.11 \times 10^{6}$ & $3.31 \times 10^{5}$ & 0 & $1.21 \times 10^{6}$ & N/A & N/A \\
\hline Port Washington & $3.42 \times 10^{8}$ & $2.70 \times 10^{6}$ & $2.95 \times 10^{5}$ & $1.16 \times 10^{5}$ & $2.99 \times 10^{5}$ & 0 & $5.64 \times 10^{3}$ \\
\hline Lakeside & $1.41 \times 10^{8}$ & $3.07 \times 10^{8}$ & $6.29 \times 10^{5}$ & 0 & 0 & N/A & N/A \\
\hline Oak Creek & $8.93 \times 10^{8}$ & $6.14 \times 10^{6}$ & $1.59 \times 10^{6}$ & $5.96 \times 10^{4}$ & $4.41 \times 10^{6}$ & N/A & N/A \\
\hline Waukegan & $4.08 \times 10^{8}$ & $2.93 \times 10^{9}$ & $1.18 \times 10^{7}$ & $2.73 \times 10^{7}$ & $1.37 \times 10^{5}$ & N/A & N/A \\
\hline Stateline & $5.26 \times 10^{8}$ & $7.12 \times 10^{8}$ & $2.97 \times 10^{6}$ & $3.61 \times 10^{6}$ & $8.07 \times 10^{4}$ & N/A & N/A \\
\hline Mitchell & $2.24 \times 10^{8}$ & $1.51 \times 10^{9}$ & $7.41 \times 10^{6}$ & $2.32 \times 10^{5}$ & $1.34 \times 10^{6}$ & $\mathrm{~N} / \mathrm{A}$ & $\mathrm{N} / \mathrm{A}$ \\
\hline Campbell & $3.35 \times 10^{8}$ & $6.48 \times 10^{4}$ & $2.25 \times 10^{3}$ & $1.24 \times 10^{2}$ & $1.49 \times 10^{3}$ & 0 & 0 \\
\hline Palisades & $9.94 \times 10^{7}$ & 0 & $7.00 \times 10^{\circ}$ & $1.40 \times 10^{1}$ & $1.30 \times 10^{1}$ & 0 & 0 \\
\hline Big Rock & $1.07 \times 10^{8}$ & 0 & $1.05 \times 10^{1}$ & $5.47 \times 10^{2}$ & $1.43 \times 10^{2}$ & 0 & 0 \\
\hline Total observed & $7.04 \times 10^{9}$ & $1.05 \times 10^{10}$ & $1.33 \times 10^{8}$ & $8.98 \times 10^{7}$ & $2.06 \times 10^{7}$ & $6.38 \times 10^{6}$ & $6.01 \times 10^{5}$ \\
\hline $\begin{array}{l}\text { Estimated annual } \\
\text { total }\end{array}$ & & $1.11 \times 10^{10}$ & $2.01 \times 10^{8}$ & $3.10 \times 10^{8}$ & $2.71 \times 10^{7}$ & $6.77 \times 10^{6}$ & $6.12 \times 10^{5}$ \\
\hline
\end{tabular}

dent on time of year and location. Almost $90 \%$ of the alewives were impinged at only 4 of the 15 plants. Maximum impingement of alewives occurred from May through July; this reflects the inshore spawning migrations of adults rather than seasonal changes in total cooling-water flow. Alewife impingement and commercial catch of alewife follow the same seasonal pattern (Fig. 2). Both the fishery and the power plants capture alewives as they move inshore to spawn.

An estimated $1.11 \times 10^{10}$ alewife eggs and $2.01 \times 10^{8}$ alewife larvae were entrained at the 15 sampled intakes in 1975 (Table 2). Entrainment of alewife eggs was highest from May through August and entrainment of larvae was highest from June through September. No eggs were entrained from October to March and no larvae were entrained from January through April.

Rainbow smelt impingement at the sampled intakes was estimated at $9.77 \times 10^{3} \mathrm{~kg}$ in 1975 (Table 1). Four plants on the western shore of Lake Michigan accounted for about $94 \%$ of the total impingement. Peaks in rainbow smelt impingement occurred during the spawning period in April and smaller peaks also occurred in July and October; impingement decreased during the winter months. An estimated $3.10 \times 10^{8}$ rainbow smelt eggs and $2.71 \times 10^{7}$ larvae were entrained at the 15 sampled intakes in 1975 (Table 2). Entrainment was highest in April for eggs and highest in May and August for larvae. Entrainment occurred from March through June for eggs and from May through November for larvae.

Yellow perch impingement at the sampled intakes was estimated as $3.11 \times 10^{3} \mathrm{~kg}$ in 1975 (Table 1). Almost $85 \%$ of the total biomass was impinged at three power plants. Impingement was highest in late fall and early winter, but a spawning-related peak occurred in May. An estimated $6.77 \times 10^{6}$ eggs and $6.12 \times 10^{5}$ yellow perch larvae were entrained in 1975 (Table 2). Eggs were entrained between March and July and larvae were entrained between May and July.

Impingement and entrainment data represent fish losses at 15 of the 22 power plants located on Lake Michigan. To assess the total impact of water withdrawal we developed a list of all other water intakes and their capacity flows. Annual impingement and entrainment for unsampled intakes was estimated by multiplying the mean impingement and entrainment rates at all sampled plants in the same fishery statistical district by the capacity flows at unsampled intakes. The 15 sampled power plants account for almost $50 \%$ of the water withdrawn (Table 3). 
TABLE 3.-Estimates of biomass impinged $(\mathrm{kg})$ and numbers of eggs and larvae entrained for three fish species at all power plant, municipal, industrial, and other water intakes on Lake Michigan, 1975. Full design flows are assumed. ${ }^{\text {a }}$

\begin{tabular}{llccc}
\hline Species & \multicolumn{1}{c}{ Impact } & $\begin{array}{c}\text { Total all } \\
\text { power plants }\end{array}$ & $\begin{array}{c}\text { Municipal } \\
\text { industrial }\end{array}$ & $\begin{array}{c}\text { Total } \\
\text { all intakes }\end{array}$ \\
\hline Alewife & Impingement & $1.65 \times 10^{6}$ & $4.56 \times 10^{5}$ & $2.10 \times 10^{6}$ \\
& Egg entrainment & $4.56 \times 10^{\mathbf{1 0}}$ & $2.83 \times 10^{10}$ & $7.39 \times 10^{10}$ \\
Yellow perch & Larvae entrainment & $1.10 \times 10^{9}$ & $2.14 \times 10^{8}$ & $1.31 \times 10^{9}$ \\
& Impingement & $1.25 \times 10^{4}$ & $6.20 \times 10^{2}$ & $1.31 \times 10^{4}$ \\
& Egg entrainment & $4.75 \times 10^{7}$ & $6.49 \times 10^{5}$ & $4.81 \times 10^{7}$ \\
Rainbow smelt & Larvae entrainment & $3.08 \times 10^{8}$ & $1.81 \times 10^{5}$ & $3.26 \times 10^{6}$ \\
& Impingement & $1.66 \times 10^{4}$ & $2.07 \times 10^{3}$ & $1.86 \times 10^{4}$ \\
& Egg entrainment & $4.71 \times 10^{8}$ & $1.44 \times 10^{8}$ & $6.15 \times 10^{8}$ \\
\hline
\end{tabular}

a Annual maximum flows: total, all power plants, $4.18 \times 10^{10} \mathrm{~m}^{3}$; total, municipal and industrial, $6.51 \times 10^{9} \mathrm{~m}^{3}$; total, all intakes, $4.83 \times 10^{10} \mathrm{~m}^{3}$.

\section{Model Development}

The surplus-production and dynamic-pool models were applied for stock assessment. Surplus production is the amount of biomass that can be removed from a population without causing a change in population size. Biomass removed is replaced by increased reproduction and growth. In the surplus-production model it is assumed that surplus production is some function of population size. The most widely applied surplus-production model is the logistic model in which change in yield and biomass with respect to time are given by the equations (Jensen 1976):

$$
\begin{aligned}
& \frac{\mathrm{d} Y}{\mathrm{~d} t}=q E B ; \\
& \frac{\mathrm{d} B}{\mathrm{~d} t}=k B-\frac{k}{B_{\infty}} B^{2}-q E B ;
\end{aligned}
$$

$B=$ biomass of the exploited stocks $(\mathrm{kg})$;

$q=$ catchability coefficient (unit of effort $x$ (ime) $)^{-1}$

$k=$ population growth constant $\left(\right.$ year $\left.^{-1}\right)$;

$Y=$ cumulative yield from the fishery $(\mathrm{kg})$;

$E=$ fishing effort (variable units);

$B_{\infty}=$ the environmental carrying capacity in terms of biomass $(\mathrm{kg})$;

$t=$ time in years.

The model was expanded to include impingement and entrainment. For the $i$ th water intake the accumulation of impinged fish biomass with respect to time is

$$
\frac{\mathrm{d} I_{i}}{\mathrm{~d} t}=f_{i} Q_{i} B
$$

$I_{i}=$ biomass $(\mathrm{kg})$ impinged at the $i$ th water intake at time $t$;

$Q_{i}=$ volume flow at the $i$ th water intake $\left(\mathrm{m}^{3} /\right.$ year);

$f_{i}=$ impingement coefficient at the $i$ th intake $\left(\mathrm{m}^{-3}\right)$.

The total impingement at $n$ water intakes at time $t$ is

$$
I=I_{1}+I_{2}+\ldots+I_{n},
$$

and the rate of impingement lakewide is

$$
\frac{\mathrm{d} I}{\mathrm{~d} t}=\sum_{i=1}^{n} f_{i} Q_{i} B
$$

The rate of entrainment of eggs at the $i$ th water intake is

$$
\frac{\mathrm{d} P_{i}}{\mathrm{~d} t}=p_{i} Q_{i} G
$$

$P_{i}=$ number of eggs entrained at the $i$ th water intake;

$G=$ abundance of eggs in the lake (numbers);

$p_{i}=$ egg entrainment coefficient $\left(\mathrm{m}^{-3}\right)$.

To relate entrainment of eggs to biomass of the exploited stock, we assume egg production is proportional to stock biomass. This is equivalent to the assumption that a percentage reduction in eggs results in the same percentage reduction in biomass of the exploited stock; there is no density dependence. Most fishery scientists assume prerecruitment mortality is density dependent (Beverton and Holt 1957; Ricker 1975). Our assumption is conservative 
TABLE 4.-Total catch and effort for alewife, rainbow smelt, and yellow perch in Lake Michigan, 1960-1977. (United States Fish and Wildlife Service, Great Lakes Laboratory, Ann Arbor, Michigan.)

\begin{tabular}{|c|c|c|c|c|c|c|}
\hline \multirow[b]{2}{*}{ Year } & \multicolumn{2}{|c|}{ Alewife } & \multicolumn{2}{|c|}{ Yellow perch } & \multicolumn{2}{|c|}{ Rainbow smelt } \\
\hline & Yield & Effort $^{a}$ & Yield & Effort $^{\mathrm{a}}$ & Yield & Effort ${ }^{b}$ \\
\hline 1960 & $1,057,103$ & 2,621 & $1,489,562$ & 57,444 & $1,479,932$ & 4,841 \\
\hline 1961 & $1,449,346$ & 2,327 & $2,574,813$ & 98,958 & 715,538 & 2,620 \\
\hline 1962 & $3,456,625$ & 8,501 & $2,039,568$ & 59,269 & 702,333 & 2,186 \\
\hline 1963 & $2,448,165$ & 24,582 & $2,210,272$ & 50,186 & 526,710 & 2,045 \\
\hline 1964 & $5,326,641$ & 11,546 & $2,646,878$ & 91,459 & 404,620 & 959 \\
\hline 1965 & $6,353,358$ & 7,425 & 695,885 & 49,878 & 419,599 & 1,124 \\
\hline 1966 & $13,155,789$ & 12,118 & 406,440 & 30,426 & 503,533 & 1,087 \\
\hline 1967 & $19,054,064$ & 16,742 & 573,967 & 27,501 & 554,953 & 812 \\
\hline 1968 & $12,285,364$ & 11,462 & 235,669 & 15,364 & 811,191 & 944 \\
\hline 1969 & $13,330,230$ & 10,050 & 291,719 & 15,719 & $1,125,453$ & 641 \\
\hline 1970 & $15,114,488$ & 10,203 & 313,820 & 17,628 & 923,976 & 482 \\
\hline 1971 & $13,450,181$ & 7,599 & 338,270 & 18,324 & 588,707 & 369 \\
\hline 1972 & $14,076,502$ & 7,767 & 465,686 & 20,050 & 312,880 & 177 \\
\hline 1973 & $16,584,780$ & 11,872 & 339,997 & 20,372 & 393,846 & 336 \\
\hline 1974 & $20,663,696$ & 10,131 & 587,902 & 32,909 & 774,028 & 341 \\
\hline 1975 & $15,961,428$ & 7,730 & 344,354 & 22,946 & 527,318 & 208 \\
\hline 1976 & $17,786,288$ & 7,918 & 387,206 & 31,864 & 983,727 & 303 \\
\hline 1977 & $21,959,808$ & 7,931 & 439,831 & 44,057 & 331,362 & 300 \\
\hline
\end{tabular}

${ }^{\text {a }}$ Equivalent pound-net lifts.

${ }^{\mathrm{b}}$ Equivalent trap-net lifts.

and increases the impact of entrainment on stock biomass and yield because there is no compensatory decrease in natural mortality. The relation between eggs and biomass is

$$
G=\left(\frac{B}{2}\right) E U B,
$$

where $E U B$ is the number of eggs produced per unit of female biomass. Lakewide, the change in biomass as a result of egg entrainment, $(\mathrm{d} B / \mathrm{d} t)_{P}$, is (see Appendix for derivation)

$$
\left(\frac{\mathrm{d} B}{\mathrm{~d} t}\right)_{p}=-\sum_{i=1}^{n} p_{i} Q_{i} B
$$

The rate of larval entrainment at the $i$ th water intake is

$$
\frac{\mathrm{d} H_{i}}{\mathrm{~d} t}=h_{i} Q_{i} L
$$

$H_{i}=$ number of larvae entrained at the $i$ th water intake;

$L=$ abundance of larvae in the lake (numbers);

$h_{i}=$ larval entrainment coefficient $\left(\mathrm{m}^{-3}\right)$.

The abundance of larvae was related to egg abundance by the survival equation

$$
L=(1-\phi) G,
$$

where $\phi$ is an egg mortality coefficient. The lakewide change in exploitable biomass resulting from larvae entrainment, $(\mathrm{d} B / \mathrm{d} t)_{H}$, is (see Appendix for derivation)

$$
\left(\frac{\mathrm{d} B}{\mathrm{~d} t}\right)_{H}=-\sum_{i=1}^{n} h_{i} Q_{i} B .
$$

Equations (1)-(11) combine to give the biomass equation

$$
\begin{aligned}
\frac{\mathrm{d} B}{\mathrm{~d} t}= & k B-\frac{k}{B_{\infty}} B^{2}-q E B-\sum_{i=1}^{n} f_{i} Q_{i} B \\
& -\sum_{i=1}^{n} p_{i} Q_{i} B-\sum_{i=1}^{n} h_{i} Q_{i} B .
\end{aligned}
$$

Application of Equation (12) requires estimation of three biological parameters and many related to the water intakes.

In the dynamic-pool model, growth and mortality are modeled as functions of age. The structure and parameters of this model are easily interpreted biologically and this model has been widely applied for stock assessment. The conventional equations applied for yield, mortality, and growth are

$$
\begin{aligned}
& \frac{\mathrm{d} Y}{\mathrm{~d} x}=F N W \\
& \frac{\mathrm{d} N}{\mathrm{~d} x}=-(M+F) N, \quad x>x_{c} ;
\end{aligned}
$$


TABLE 5.-Estimates of biological parameters for the surplus-production model: population growth constant, k; carrying capacity, $\mathrm{B}_{\infty}$; and catchability coefficient, $\mathrm{q}$.

\begin{tabular}{|c|c|c|c|}
\hline Species & $\begin{array}{c}k \\
\left(\text { year }^{-1}\right)\end{array}$ & $\begin{array}{c}B_{\infty} \\
(\mathrm{kg})\end{array}$ & $\begin{array}{c}q \\
(\text { effort } \\
\text { time }\end{array}$ \\
\hline Alewife & 0.30 & $400,000,000$ & 0.00001 \\
\hline Yellow perch (lakewide) & 0.20 & $15,000,000$ & 0.0000014 \\
\hline \multicolumn{4}{|c|}{ Yellow perch (Green } \\
\hline Bay) & 0.20 & $7,000,000$ & 0.0000015 \\
\hline Rainbow smelt & 0.50 & $20,000,000$ & 0.0001 \\
\hline
\end{tabular}

$$
\frac{\mathrm{d} W}{\mathrm{~d} x}=3 K W_{\infty} e^{-K x}\left(1-e^{-K x}\right)^{2} ;
$$

$Y=$ annual yield;

$F=$ instantaneous fishing mortality coefficient $\left(\right.$ year $\left.^{-1}\right)$;

$N=$ number of individuals of age $x$;

$W=$ weight of an individual of age $x(\mathrm{~kg})$;

$M=$ instantaneous natural mortality coefficient $\left(\right.$ year $\left.^{-1}\right)$;

$W_{\infty}=$ asymptotic individual weight $(\mathrm{kg})$;

$K=$ growth coefficient $\left(\right.$ year $\left.^{-1}\right)$;

$x_{c}=$ age when individuals become vulnerable to fishing (years).

The relation between the rate of impingement and biomass is the same as in the surplusproduction model (Equation 5). The impact of impingement occurs through an increase in mortality; with impingement the mortality equation becomes

$$
\begin{aligned}
& \frac{\mathrm{d} N}{\mathrm{~d} x}=-\left(M+\sum_{i=1}^{n} f_{i} Q_{i}\right) N, \quad x_{I} \leqslant x<x_{c} \\
& \frac{\mathrm{d} N}{\mathrm{~d} x}=-\left(M+F+\sum_{i=1}^{n} f_{i} Q_{i}\right) N, \quad x \geqslant x_{c},
\end{aligned}
$$

where $x_{I}$ is the age when fish first become vulnerable to impingement. Biomass of the exploited stock is

$$
B=\int_{x_{\mathrm{c}}}^{\infty} N W \mathrm{~d} x,
$$

which gives, on substitution and integration,

$$
\begin{aligned}
B= & R W_{\infty} e^{-\left(M+\sum_{i=1}^{n} f_{i} Q_{i}\right)\left(x_{c}-x_{i}\right)} \\
& \cdot \sum_{m=0}^{3} \frac{U_{m} e^{m K x_{c}}}{F+M+\sum_{i=1}^{n} f_{i} Q_{i}+m K},
\end{aligned}
$$

where $U_{0}=1, U_{1}=-3, U_{2}=3$, and $U_{3}=-1$. The number of fish of age $x_{I}$ is recruitment, $R$. The above biomass equation was applied to calculate biomass of the exploited stock.

Entrainment of eggs and larvae operates on the recruitment term. The equations for rate of entrainment of eggs and larvae are identical to those for the surplus-production model (Equations 6 and 9). In the dynamic-pool mod$\mathrm{el}$, however, change occurs in the number of eggs and larvae over time. Change in the number of eggs is given by

$$
\frac{\mathrm{d} G}{\mathrm{~d} x}=-\left(M_{1}+\sum_{i=1}^{n} p_{i} Q_{i}\right) G
$$

where $M_{1}$ is an egg natural mortality coefficient. The initial number of eggs is $G(0)=$ $E U B \cdot B / 2$ and the number of eggs at age $x$ is

$$
G(x)=G(0) e^{-\left(M_{1}+\sum_{i=1}^{n} p_{1} Q_{1}\right) x} .
$$

Change in the number of larvae with respect to age is

$$
\frac{\mathrm{d} L}{\mathrm{~d} x}=-\left(M_{2}+\sum_{i=1}^{n} h_{i} Q_{i}\right) L,
$$

where $M_{2}$ is a natural mortality coefficient for larvae. The number of individuals of age $x_{I}$, when fish first become vulnerable to impingement, is

$$
R=G(0) e^{-\left(M_{1}+\sum_{i=1}^{n} p_{i} Q_{i}\right) \Delta x_{1}-\left(M_{2}+\sum_{i=1}^{n} h_{i} Q_{i}\right) \Delta x_{2}},
$$

where $\Delta x_{1}$ is the duration of the egg stage in years and $\Delta x_{2}$ is the duration of the larval stage. In this model, mortality during the prerecruitment stages is density independent, which will increase the impact of entrainment. The recruitment equation can be substituted into the biomass equation to give an equation for assessment of the combined impacts of entrainment and impingement on the biomass of the standing stock and yield.

\section{Parameter Estimation}

The biological parameters of the surplusproduction model, $k, B_{\infty}$, and $q$, were estimated from the commercial fishery catch and effort data for the years 1960-1977 (Table 4). The data are recorded separately for each of several fishery statistical districts (Fig. 1), and for each species the catch is recorded separately for each 


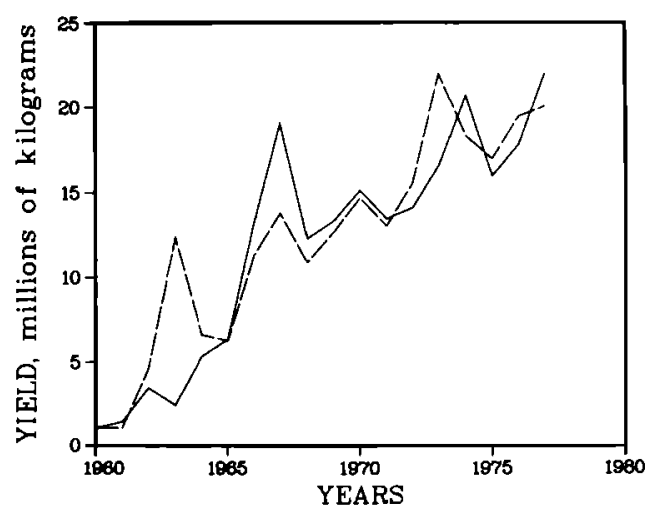

FIGURE 3.-Observed yield (solid line) and yield predicted by the surplus-production model (dashed line) for alewife in Lake Michigan.

type of fishing gear. To enable use of data for all districts and all years, a standard gear was selected for each species and the total effort necessary to make the observed catch with the standard gear was calculated as

$$
\text { total effort }=\frac{\text { total catch }}{\text { CPUE with standard gear }} \text {, }
$$

where CPUE is catch per unit of effort.

For estimation of $k, B_{\infty}$, and $q$ (Table 5) nonlinear least squares was applied to minimize the residual sum of squares between the observed and calculated yields (Pella and Tomlinson 1969). For a set of parameters, calculated yields were obtained from the solution of the yield equation (Equation 1). The solution to the yield equation was approximated by use of the trapezoidal rule and the necessary biomass values were calculated from the solution of the biomass equation (Equation 2).

To estimate the proportion of larvae entrained, the egg mortality coefficient, $\phi$, must be estimated. Estimates of egg mortality vary from $50 \%$ to $75 \%$ for yellow perch in Lake Erie (Patterson 1979), but estimation of mortality under natural conditions is difficult and few data are available. Under the assumption of an equilibrium between population size and egg production, the mortality of the prerecruitment life stages can be calculated. Under the assumption that most of this mortality occurs in the egg stage, $\phi$ was set at 0.99 for all species. This large value does not influence the estimate of egg-entrainment impact but it is likely to result in an overestimate of larval-entrainment

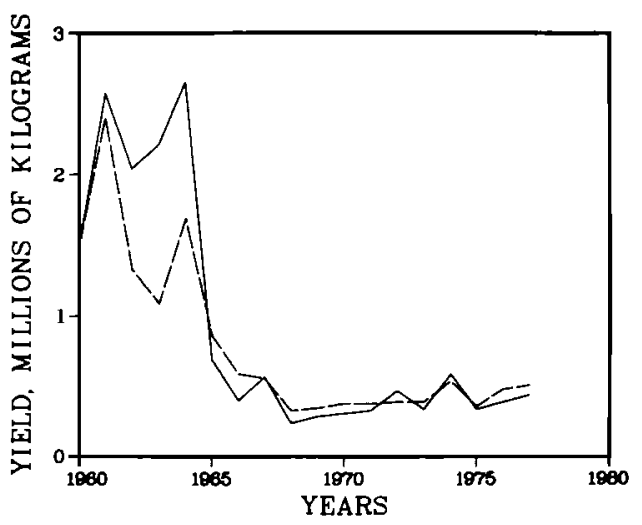

FIGURE 4.-Observed yield (solid line) and yield predicted by the surplus-production model (dashed line) for yellow perch in Lake Michigan.

impact because it underestimates the number of larvae.

Estimates of the number of eggs produced per unit of biomass, EUB, were obtained from the literature. The number of eggs produced per kilogram of alewife female was estimated as 368,000 which is 14,000 eggs per female of average weight (Norden 1967). From data published by Brazo et al. (1975), yellow perch egg production was estimated as 65,000 per kilogram, which is about 17,000 per average female. Rainbow smelt egg production per kilogram of female was estimated as $1,000,000$, which is about 15,000 eggs per average female of age 2 and length $153 \mathrm{~mm}$ (Van Oosten 1940; Bailey 1964).

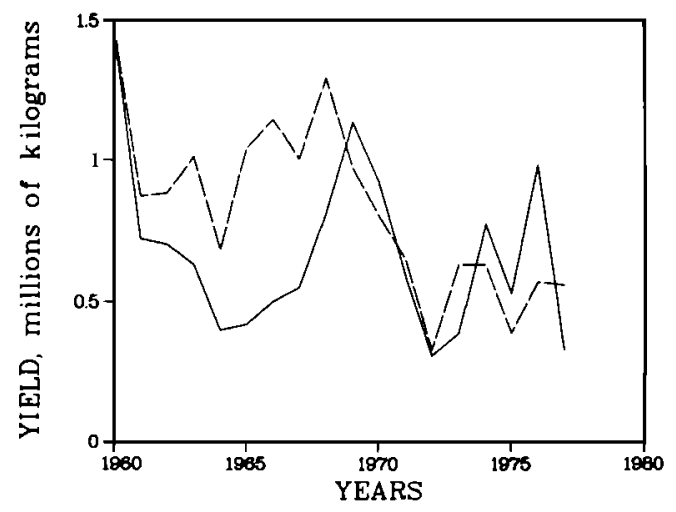

FIGURE 5.-Observed yield (solid line) and yield predicted by the surplus-production model (dashed line) for rainbow smelt in Lake Michigan. 
TABLE 6.-Entrainment and impingement coefficients for Lake Michigan power plants.

\begin{tabular}{|c|c|c|c|c|c|c|c|}
\hline \multirow[b]{2}{*}{ Species } & \multirow[b]{2}{*}{ Coefficient } & \multicolumn{3}{|c|}{ Surplus-production model } & \multicolumn{3}{|c|}{ Dynamic-pool model } \\
\hline & & Mean & Maximum & Minimum & Mean & Maximum & Minimum \\
\hline \multirow[t]{3}{*}{ Alewife } & Impingement & $0.11 \times 10^{-12}$ & $0.27 \times 10^{-12}$ & $0.25 \times 10^{-15}$ & $0.89 \times 10^{-13}$ & $0.36 \times 10^{-12}$ & $0.21 \times 10^{-15}$ \\
\hline & Egg entrainment & $0.17 \times 10^{-13}$ & $0.17 \times 10^{-12}$ & $0.64 \times 10^{-17}$ & $0.69 \times 10^{-14}$ & $0.38 \times 10^{-11}$ & $0.14 \times 10^{-15}$ \\
\hline & Larvae entrainment & $0.22 \times 10^{-15}$ & $0.17 \times 10^{-14}$ & $0.28 \times 10^{-20}$ & $0.69 \times 10^{-16}$ & $0.39 \times 10^{-13}$ & $0.36 \times 10^{-17}$ \\
\hline \multirow{3}{*}{$\begin{array}{l}\text { Yellow } \\
\text { perch }\end{array}$} & Impingement & $0.67 \times 10^{-14}$ & $0.64 \times 10^{-12}$ & $0.99 \times 10^{-16}$ & $0.30 \times 10^{-13}$ & $0.60 \times 10^{-12}$ & $0.12 \times 10^{-15}$ \\
\hline & Egg entrainment & $0.29 \times 10^{-14}$ & $0.18 \times 10^{-13}$ & $0.62 \times 10^{-16}$ & $0.49 \times 10^{-15}$ & $0.75 \times 10^{-13}$ & $0.26 \times 10^{-15}$ \\
\hline & Larvae entrainment & $0.39 \times 10^{-16}$ & $0.36 \times 10^{-14}$ & $0.71 \times 10^{-16}$ & $0.40 \times 10^{-16}$ & $0.15 \times 10^{-13}$ & $0.79 \times 10^{-16}$ \\
\hline \multirow{3}{*}{$\begin{array}{c}\text { Rainbow } \\
\text { smelt }\end{array}$} & Impingement & $0.37 \times 10^{-13}$ & $0.31 \times 10^{-12}$ & $0.79 \times 10^{-16}$ & $0.38 \times 10^{-13}$ & $0.32 \times 10^{-12}$ & $0.81 \times 10^{-16}$ \\
\hline & Egg entrainment & $0.22 \times 10^{-13}$ & $0.16 \times 10^{-12}$ & $0.30 \times 10^{-16}$ & $0.12 \times 10^{-11}$ & $0.84 \times 10^{-11}$ & $0.16 \times 10^{-14}$ \\
\hline & Larvae entrainment & $0.21 \times 10^{-14}$ & $0.26 \times 10^{-14}$ & $0.91 \times 10^{-1 \theta}$ & $0.89 \times 10^{-13}$ & $0.49 \times 10^{-12}$ & $0.48 \times 10^{-17}$ \\
\hline
\end{tabular}

The fits of the surplus-production model to the observed catch data are good for alewife and yellow perch (Figs. 3 and 4 ). The coefficients of determination $R^{2}$ are 0.78 for alewife, 0.85 for yellow perch, and 0.28 for rainbow smelt. The model does not accurately describe the catch of rainbow smelt from 1960 to about 1969 (Fig. 5) but since 1970 the fit is better $\left(R^{2}=0.56\right)$.

Estimates of the impingement and entrainment coefficients (Table 6) were obtained from the surplus-production model by replacing the differential equations with difference equations. The resulting estimators are

$$
\begin{aligned}
& f_{i}=\frac{\Delta I_{i}}{Q_{i} B^{*}}, \\
& h_{i}=\frac{\Delta H_{i}}{Q_{i} B^{*}}, \text { and } \\
& p_{i}=\frac{\Delta P_{i}}{Q_{i} B^{*}} .
\end{aligned}
$$

Numerators are the observed biomass impinged and the observed numbers of eggs and larvae entrained. For application of the surplus-production model, the average biomass during the year, $B^{*}$, was estimated from the surplus-production model. Water-flow, entrainment, and impingement data are in Tables 1 and 2.

Parameter estimates for the dynamic-pool model (Table 7) were obtained directly from the literature or were calculated from data therein. Length, weight, and age data for alewife were reported by Brown (1972). The growth parameters $\left(K=0.31 ; W_{\infty}=0.12 \mathrm{~kg}\right)$ were estimated from these data by conventional procedures (Gulland 1969) and the exponent in the length-weight equation is 3.01 . The total instantaneous mortality coefficient $Z$ was estimated as 0.50 from age structure data reported by Edsall et al. (1974). With the estimate of $q$ obtained with the surplus-production model and the observed average fishing effort, the instantaneous fishing mortality coefficient was estimated as $F=q E=0.06$.

Much of the biological data for yellow perch in Lake Michigan is summarized by Brazo et al. (1975). From these data the growth parameters were estimated as $K=0.45$ and $W_{\infty}=1.0 \mathrm{~kg}$. It was assumed that the slope of the lengthweight relation was 3 . The total mortality coefficient was estimated as 0.36 , and from $q$ and the average fishing effort, the fishing mortality coefficient was estimated as 0.06. Parameters for rainbow smelt were estimated from Bailey's (1964) data.

The equations for parameters related to power plants in the surplus-production model were applied for the dynamic-pool model (Table 6). Biomass in these equations was estimated by the dynamic-pool model.

\section{Impact Assessment}

Both the surplus-production model and the dynamic-pool model were applied to estimate stock biomass, the proportions of the standing stocks impinged, and the proportions of eggs and larvae entrained. The surplus-production model also was applied to estimate the reductions in biomass and yield resulting from increased entrainment and impingement. Applications of the surplus-production and dynamic-pool models were kept as independent as possible so a comparison of the results obtained by the two models could be used as a basis for evaluation. Of the dynamic-pool mod- 
TABLE 7.-Estimates of parameters for the dynamic-pool model for alewife, yellow perch, and rainbow smelt in Lake Michigan.

\begin{tabular}{|c|c|c|c|c|}
\hline Parameters & Symbol & Alewife & Yellow perch & Rainbow smelt \\
\hline Asymptotic weight $(\mathrm{kg})$ & $W_{x}$ & 0.1164 & 1.0 & 0.03 \\
\hline Average weight $(\mathrm{kg})$ & $W_{\text {avg }}$ & 0.0392 & 0.265 & 0.0140 \\
\hline Catchable age (year) & $x_{c}$ & 2.0 & 3.0 & 2.0 \\
\hline Impingeable age (year) & $x_{I}$ & 1.0 & 1.0 & 1.0 \\
\hline Instantaneous fishing mortalicy coefficient $\left(\right.$ year $\left.^{-1}\right)$ & $F$ & 0.06 & 0.06 & 0.03 \\
\hline Instantaneous natural mortality coefficient (year ${ }^{-1}$ ) & $M$ & 0.50 & 0.30 & 0.40 \\
\hline Age at maturity (year) & $x_{\text {mat }}$ & 2.0 & 2.00 & 2.0 \\
\hline Growth parameter (year ${ }^{-1}$ ) & $K$ & 0.31 & 0.45 & 0.56 \\
\hline Eggs per unit biomass (kg) & $E U B$ & 368,000 & 65,316 & $1,073,370$ \\
\hline Egg mortality coefficient $\left(\right.$ year $^{-1}$ ) & $M_{1}$ & 11.51 & 11.51 & 11.51 \\
\hline Larvae mortality coefficient $\left(\right.$ year $^{-1}$ ) & $M_{2}$ & 5.50 & 5.50 & 5.50 \\
\hline Duration of egg stage (year) & $\Delta x_{1}$ & 0.10 & 0.10 & 0.10 \\
\hline Duration of larvae stage (year) & $\Delta x_{2}$ & 1.00 & 1.00 & 1.00 \\
\hline
\end{tabular}

el parameter estimates, only the value for $F$ came from the surplus-production model. The estimates of percentages impinged and entrained under the assumption of full flow at the 15 power plants are listed in Table 8 . Alewives were the most frequently impinged and entrained, and the percentages of the alewife population impinged and entrained were also the highest, among the three species.

The proportions of biomass impinged are similar within each species for both models, but the estimates of proportions entrained are considerably different for the two models (Table 8). All of the parameters for estimation of impingement impact were estimated directly from the data, but for estimation of entrainment impact key parameters were of necessity estimated indirectly. Apparently, these estimates are not accurate. Although the percentages of eggs and larvae entrained are higher with the dynamicpool model, the impact of entrainment on the biomass of the standing stock and yield is still small compared to the impact of impingement. If the impacts of entrainment were large, there would have been a need to more accurately estimate the egg and larvae mortality parameters.

The surplus-production model was applied to estimate the impact of the total capacity for water withdrawal from Lake Michigan-4.8 $\times$ $10^{10} \mathrm{~m}^{3} /$ year - and to simulate the impact of increased water withdrawals on the biomass of the standing stock and the maximum sustainable yield. Under equilibrium conditions where $\mathrm{d} B / \mathrm{d} t=0$, the biomass equation with average impingement and entrainment coefficients $f, p$, and $h$ is

$$
B=B_{\infty}-\frac{q E B_{\infty}}{k}-\frac{(f+p+h) B_{\infty}}{k} .
$$

With these coefficients, the relation between biomass and withdrawal flow for alewife is $B=$ $2.79 \times 10^{8}-0.00002 Q$ (Fig. 6), the equation for yellow perch is $B=1.23 \times 10^{7}-0.0003 Q$, and the equation for rainbow smelt is $B=$ $1.56 \times 10^{7}-0.000002 Q$. Increasing the volume of water withdrawn results in a slow linear decrease in the size of the standing stock. The impact of impingement is larger than that of entrainment. At withdrawals of $4.8 \times 10^{10} \mathrm{~m}^{3} /$ year, biomasses are reduced $2.86 \%$ for alewife, $0.28 \%$ for yellow perch, and $0.76 \%$ for rainbow smelt, compared with no-flow conditions. When maximum entrainment and impingement coefficients (Table 6) are applied to the total flow, there is about a $10 \%$ decrease in biomass.

The impact of water withdrawal on the max-

TABLE 8.-Estimates of percentages entrained and impinged at 15 Lake Michigan power plants operating at full water flow, calculated with surplus-production and dynamic-pool models.

\begin{tabular}{llll}
\hline \multirow{2}{*}{ Species } & \multicolumn{1}{c}{ Impact } & \multicolumn{2}{c}{ Surplus- } \\
production & Dynamic- & pool \\
\hline Alewife & Impingement $(\mathrm{kg})$ & 0.25 & 0.21 \\
& Egg entrainment & 0.04 & 0.90 \\
\multirow{3}{*}{ Yellow perch } & Larvae entrainment & 0.90 & 2.0 \\
& lmpingement (kg) & 0.07 & 0.05 \\
& Egg entrainment & 0.007 & 0.02 \\
Rainbow smelt & Larvae entrainment & 0.03 & 0.14 \\
& lmpingement (kg) & 0.15 & 0.15 \\
& Egg entrainment & 0.00008 & 0.043 \\
& Larvae entrainment & 0.00033 & 0.174 \\
\hline
\end{tabular}




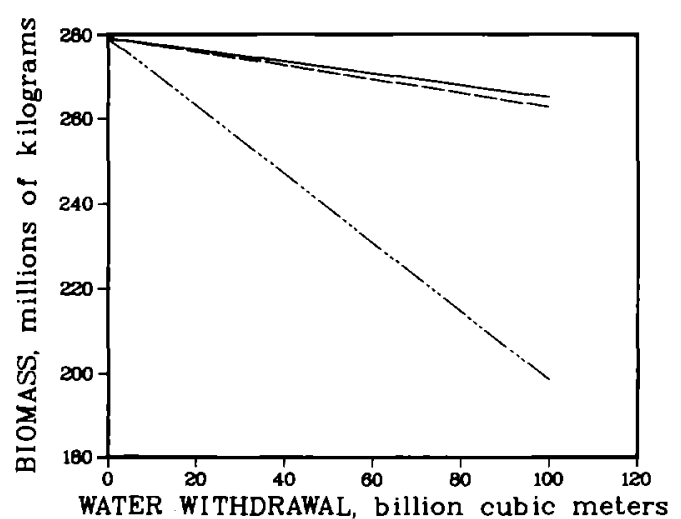

FIGURE 6.-Effects of water withdrawal on the biomass of alewife in Lake Michigan when average impingement (top line), average impingement and entrainment (middle line), and maximum impingement and entrainment (bottom line) coefficients are applied to the surplus-production model.

imum sustainable yield, MSY, can be found from the equilibrium yield equation

$$
Y_{\rho}=k B-\frac{k}{B_{\infty}} B^{2}-(f+h+p) Q B,
$$

where $Y_{e}$ is the annual equilibrium yield. In the presence of water withdrawals the biomass at which the maximum sustainable yield occurs is

$$
\frac{[k-(f+h+p) Q] B_{\infty}}{2 k},
$$

and substitution of this biomass into the equilibrium yield equation gives

$$
\begin{aligned}
M S Y= & \frac{k B_{\infty}}{4}-\frac{(f+h+p) Q}{2} \\
& +\frac{B_{\infty}[(f+h+p) Q]^{2}}{4 k} .
\end{aligned}
$$

The relationship between water withdrawal and maximum sustainable yield is not linear but the second degree term is small and a linear relationship is adequate. For average entrainment and impingement coefficients, the relation between water withdrawal and MSY are $M S Y=3 \times 10^{7}-0.000025 Q$ for alewife, $M S Y=5 \times 10^{5}-0.0000006 Q$ for yellow perch, and $M S Y=2.5 \times 10^{6}-0.0000006 Q$ for rainbow smelt. Increased water withdrawal causes a slow decrease in the MSY. At a withdrawal rate of $4.8 \times 10^{10} \mathrm{~m}^{3} /$ year, the reductions in MSY are $4 \%$ for alewife, $0.5 \%$ for yellow perch, and $1.2 \%$ for rainbow smelt.

\section{Discussion}

Our estimates of biomass impinged are higher than those reported by Kelso and Milburn (1979). Their estimate of the average weight of an impinged fish $(0.075 \mathrm{~kg})$ applied to their observed total number impinged in Lake Michigan gives $1.15 \times 10^{6} \mathrm{~kg}$ impinged. They assumed that this was an underestimate because it was made from a regression of numbers impinged on rated megawatt capacity. Using full design volume flow, we assume our estimate of $1.65 \times 10^{6} \mathrm{~kg}$ impinged is an overestimate. Despite the differences in assumptions and methods applied, these two estimates are reasonably close.

Kelso and Milburn (1979) reported that the number of fish impinged amounted to $25 \%$ of the total commercial catch on the Great Lakes. Most impinged fish are small alewives and a more meaningful comparison of impingement with the commercial catch is in terms of biomass for each species. Our estimates of biomass impinged and the 1975 commercial catch statistics (Table 4) indicate that under the assumption of full flow, impingement amounted to $10 \%$ of the commercial catch of alewife, $3.6 \%$ of that of yellow perch, and $3.1 \%$ of that of rainbow smelt.

Our estimate of the number of larvae entrained also is higher than that of Kelso and Milburn (1979). We estimated the total number of larvae entrained at conventional power plants under the assumption of full flow as $4.21 \times 10^{8}$. Applying a regression of number entrained on rated megawatt capacity, Kelso and Milburn (1979) estimated $1.96 \times 10^{8}$ larvae were entrained. These two estimates are in reasonable agreement despite the different assumptions applied.

To obtain impact assessments, the observed amounts impinged and entrained must be given relative to the sizes of the populations in the lake. Direct estimation of the biomass of a fish stock is difficult and assessment of the impact of entrainment and impingement is done most easily with a model that describes the response of a population to these impacts. Fishery models are relatively simple. Effort has been directed at parameter estimation rather than toward more elaborate models. The logistic surplus-production model was developed during the late 1920s and 1930s by Volterra (1928), Hjort et al. (1933), and Graham (1935). The 
assumptions and limitations of the surplus-production model are well known and are discussed in some detail by Pella and Tomlinson (1969) and Jensen (1976). Estimation of model parameters has been examined by Schaefer (1957), Pella and Tomlinson (1969), Fox (1970), Schnute (1977), Mohn (1980), and Uhler (1980). After successful development of methods for parameter estimation by Schaefer (1957), the model was widely applied for stock assessment (Schaefer 1957; Pella and Tomlinson 1969; Schaaf and Huntsman 1972; Jensen 1976, 1978). Laboratory studies have verified the general model structure (Silliman 1971).

Application of an early form of the dynamicpool model to the fishery for Pacific halibut Hippoglossus stenolepis by Thompson and Bell (1934) was one of the most successful in fishery management (Ricker 1975). The mathematics of the model were developed mainly by Beverton and Holt (1957) and Ricker (1944). The model has been applied widely and its advantages and limitations are well known. Development and application of the model are discussed in detail by Gulland (1969).

The impact of impingement can be assessed just as that of a fishery. On the Great Lakes, both fisheries and power plants catch fish as the latter move toward shore; both operate largely on spawning stocks (Fig. 2). Seasonal fluctuations are not considered in conventional fishery assessment and they were not considered in this assessment of power plants. To model the impact of entrainment substantial modifications of the models are necessary; in this study the simplest modifications were applied. The models fit the data well and the results obtained by applying the two different models are in general agreement.

Biomass estimates generated by the models were compared with trawl-based estimates of biomass made by the United States Fish and Wildlife Service. Hatch et al. (1981) estimated the adult alewife biomass vulnerable to bottom trawling as $86,000,000$ to $131,600,000 \mathrm{~kg}$ in 1975. We estimated biomass as $206,000,000 \mathrm{~kg}$ with the surplus-production model and $237,000,000 \mathrm{~kg}$ with the dynamic-pool model (Table 9). The 1975 rainbow smelt biomass in Lake Michigan was estimated as $13,700,000 \mathrm{~kg}$ by Hatch (personal communication). We estimated the biomass of rainbow smelt as $25,000,000 \mathrm{~kg}$ with the surplus-production
TABLE 9.-Estimates of species biomass ( $\mathrm{kg}$ ) in 1975 determined for Lake Michigan by the United States Fish and Wildlife Service (Hatch 1981), surplus-production model, and dynamic-pool model (kg).

\begin{tabular}{lcrr}
\hline \multicolumn{1}{c}{ Species } & $\begin{array}{c}\text { Fish and } \\
\text { Wildlife } \\
\text { Service }\end{array}$ & $\begin{array}{c}\text { Surplus- } \\
\text { production } \\
\text { model }\end{array}$ & $\begin{array}{c}\text { Dynamic- } \\
\text { pool model }\end{array}$ \\
\hline Alewife & $122,000,000$ & $206,000,000$ & $237,000,000$ \\
Yellow perch & & $11,000,000$ & $25,000,000$ \\
Rainbow smelt & $14,000,000$ & $25,000,000$ & $15,000,000$ \\
\hline
\end{tabular}

model and $15,000,000 \mathrm{~kg}$ using the dynamicpool model (Table 9). The biomass estimates obtained with the models are somewhat higher than those based on sampling with bottom trawls, which are probably underestimates (Hatch et al, 1981). Yellow perch biomass was estimated as $11,000,000 \mathrm{~kg}$ with the surplusproduction model and $25,000,000 \mathrm{~kg}$ with the dynamic-pool model, the first such estimates for the Lake Michigan population.

Lakewide application of the models assumes complete mixing of stocks within the lake. To determine what influence this assumption might have on the results, the impact of the Pulliam Power Plant on yellow perch in Green Bay was investigated with the surplus-production model. The parameter estimates for Green Bay are $q=0.0000015, k=0.20$, and $B_{\infty}=$ $7,000,000 \mathrm{~kg}$ (Table 5). The carrying capacity $B_{x}$ of Green Bay is estimated at about $50 \%$ of the lakewide carrying capacity. The growth rates and catchability coefficients are about the same in Green Bay and Lake Michigan. The fit of the model in Green Bay is similar to the lakewide fit, and the pattern of catches is similar.

The impingement and entrainment coefficients are higher when the impact on Green Bay is assessed than when the impact on Lake Michigan is assessed. This is expected because the biomass available to the Pulliam Plant is considerably reduced when only Green Bay is under consideration. The estimate of the proportion of yellow perch in Lake Michigan impinged at the Pulliam Power Plant is $0.50 \times$ $10^{-3}$. The proportion of the biomass in Green Bay impinged is $1.0 \times 10^{-3}$. The yellow perch population of Green Bay in 1975 was about $50 \%$ of the lakewide estimate for 1975 . From the proportion of biomass in the lake impinged and the percent of the population of the lake estimated to be in Green Bay the proportion 
impinged in Green Bay is estimated as $0.50 \times$ $10^{-3}$, which is identical to the estimate obtained for Green Bay data.

This study indicates that conventional fishery models can be usefully applied for environmental-impact assessment. Accurate assessment of entrainment requires more accurate estimation of larva and egg mortality parameters than was attempted in this study, but the approach taken here appears satisfactory for identification of situations that represent threats to fisheries. Although large numbers of alewife, rainbow smelt, and yellow perch are killed by entrainment and impingement, the proportions of the populations affected are relatively small. Still, the loss of fish biomass is not negligible, and entrainment and impingement impacts need to be considered in the design of new intake facilities.

\section{Acknowledgments}

We thank the United States Environmental Protection Agency Region V Enforcement Division and the Great Lakes National Program Office for financial support and we thank G. Milburn and V. Saulys for their assistance. I. P. Murarka and R. F. Freeman did the initial data analysis. B. M. Lesht and W. R. Penrose read the manuscript. R. L. Patterson made many helpful suggestions relating to presentation of the model. Helpful comments by C. Walters also were much appreciated. S. Smith provided us with the Great Lakes catch and effort data. P. A. Tyrolt typed the manuscript.

\section{References}

BAILEy, M. M. 1964. Age, growth, maturity, and sex composition of the American smelt (Osmerus mor$d a x)$, of western Lake Superior. Transactions of the American Fisheries Society 93:382-395.

Beverton, R. J. H., and S. J. Holt, 1957. On the dynamics of exploited fish populations. Fisheries Investigations, Series II, Marine Fisheries Great Britain Ministry of Agriculture Fisheries and Food 19.

Brazo, D. C., P. I. Tack, and C. R. Liston. 1975. Age, growth, and fecundity of yellow perch, Perca flavescens, in Lake Michigan near Ludington, Michigan. Transactions of the American Fisheries Society 104:726-730.

Brown, E. H., JR. 1972. Population biology of alewives, Alosa pseudoharengus, in Lake Michigan, 1949-1970. Journal of the Fisheries Research Board of Canada 29:477-500.

Eosall, T. A., E. H. Brown, Jr., T. G. Yocum, and
R. S. C. WolcotT, JR. 1974. Utilization of alewives by coho salmon in Lake Michigan. United States Fish and Wildlife Service, Great Lakes Fisheries Laboratory, Technical Report, Ann Arbor, Michigan, USA.

Fox, W. W. 1970. An exponential surplus-yield model for optimizing exploited fish populations. Transactions of the American Fisheries Society 99:80-88.

Graham, M. 1935. Modern theory of exploiting a fishery, and applications to North Sea trawling. Journal du Conseil, Conseil International pour l'Exploration de la Mer 10:264-274.

Gulland, J. 1969. Manual of methods for fish stock assessment. Part I. Fish population analysis. FAO Manuals in Fishery Science 4. Food and Agriculture Organization of the United Nations, Rome, Italy.

Hatch, R. W., P. M. HaAck, and E. H. Brown. 1981. Estimation of alewife biomass in Lake Michigan, 1967-1978. Transactions of the American Fisheries Society 110:575-584.

HJort, J., G. Jahn, and P. Ottestad. 1933. The optimum catch. Hvalradets Skrifter 7:92-127.

Jensen, A. L. 1976. Assessment of the United States lake whitefish fisheries of Lake Superior, Lake Michigan, and Lake Huron. Journal of the Fisheries Research Board of Canada 33:747-759.

JENSEN, A. L. 1978. Assessment of the lake trout fishery in Lake Superior: 1929-1950. Transactions of the American Fisheries Society 107:543549 .

Kelso, J. R. M., and G. S. Milburn. 1979. Entrainment and impingement of fish by power plants in the Great Lakes which use the once-through cooling process. Journal of Great Lakes Research 5:182-194.

Moнn, R. K. 1980. Bias and error propagation in logistic production models. Canadian Journal of Fisheries and Aquatic Sciences 37:1276-1283.

Norden, C. R. 1967. Age, growth, and fecundity of the alewife, Alosa pseudoharengus, in Lake Michigan. Transactions of the American Fisheries Society 96:387-393.

Patterson, R. L. 1979. Production, mortality, and power plant entrainment of larval yellow perch in western Lake Erie. United States Environmental Protection Agency Research Report EPA-600/ 3-79-087 Washington, District of Columbia, USA.

Pella, J. J. And P. K. Tombinson. 1969. A generalized stock production model. Inter-American Tropical Tuna Commission Bulletin 13:419496.

Ricker, W. E. 1944. Further notes on fishing mortality and effort. Copeia 1944:23-44.

Ricker, W. E. 1975. Computation and interpretation of biological statistics of fish populations. Fisheries Research Board of Canada Bulletin 191.

SchaAf, W. E., and G. R. Hunstman. 1972. Effects of fishing on the Atlantic menhaden stock: 1955- 
1969. Transactions of the American Fisheries Society 101:290-297.

Schaefer, M. B. 1957. A study of the dynamics of the fishery for yellowfin tuna in the eastern tropical Pacific Ocean. Inter-American Tropical Tuna Commission Bulletin 2:247-268.

Schnute, J. 1977. Improved estimates from the Schaefer production model: theoretical consideration. Journal of the Fisheries Research Board of Canada 28:1211-1214.

Spigarelli, S. A., A. L. Jensen, and M. M. Thommes. 1981. Assessment of the impacts of water intakes on alewife, rainbow smelt, and yellow perch populations in Lake Michigan. United States Environmental Protection Agency Ecological Research Series EPA-905/3-81-001 Chicago, Illinois, USA.
Thompson, W. F., And F. H. Bell. 1934. Biological statistics of the Pacific halibut fishery. 2. Effect of changes in intensity upon total yield and yield per unit of gear. Report International Fisheries Commission 8.

UHLER, R. S. 1980. Least squares regression estimates of the Schaefer production model: some Monte Carlo simulation results. Canadian Journal of Fisheries and Aquatic Sciences 37:12841294.

Van Oosten, J. 1940. The smelt, Osmerus mordax (Mitchill). Michigan Department of Conservation, Lansing, Michigan, USA.

Volterra, V. 1928. Variations and fluctuations of the number of individuals in animal species living together. Journal du Conseil, Conseil International pour l'Exploration de la Mer 3:1-51.

\section{Appendix}

\section{Derivation of Equation (8)}

The relation between egg production and biomass is (Equation 7)

$$
G=\left(\frac{B}{2}\right) E U B .
$$

From this equation

$$
B=\frac{2 G}{E U B},
$$

and differentiation gives

$$
\frac{\mathrm{d} B}{\mathrm{~d} t}=\frac{2}{E U B} \frac{\mathrm{d} G}{\mathrm{~d} t} .
$$

This same relation applies for eggs entrained at a power plant,

$$
\left(\frac{\mathrm{d} B}{\mathrm{~d} t}\right)_{P}=\frac{2}{E U B}\left(\frac{\mathrm{d} G}{\mathrm{~d} t}\right)_{P},
$$

where $(\mathrm{d} G / \mathrm{d} t)_{P}$ is the rate of change in number of eggs in the lake as result of entrainment. The rate of loss of eggs from the lake as result of entrainment equals the rate of accumulation of eggs at the power plant, hence, $(\mathrm{d} G / \mathrm{d} t)_{P}=-\mathrm{d} P / \mathrm{d} t$. Therefore,

$$
\left(\frac{\mathrm{d} B}{\mathrm{~d} t}\right)_{p}=-\frac{2}{E U B} p Q G,
$$

but $G=(B / 2) E U B$ and, therefore,

$$
\left(\frac{\mathrm{d} B}{\mathrm{~d} t}\right)_{P}=-p Q B .
$$

This equation is applied to each power plant and the equations are summed to give Equation (8).

\section{Derivation of Equation (11)}

The relation between larvae production and egg production is (Equation 10)

$$
L=(1-\phi) G .
$$

Substitution for $G$ (Equation 7) gives

$$
L=(1-\phi) \frac{E U B}{2} B,
$$

and differentiation gives

$$
\frac{\mathrm{d} L}{\mathrm{~d} t}=(1-\phi) \frac{E U B}{2} \frac{\mathrm{d} B}{\mathrm{~d} t} .
$$

This same relationship applies to larvae entrained at a power plant, hence,

$$
\left(\frac{\mathrm{d} L}{\mathrm{~d} t}\right)_{H}=(1-\phi) \frac{E U B}{2}\left(\frac{\mathrm{d} B}{\mathrm{~d} t}\right)_{H},
$$

where $(\mathrm{d} L / \mathrm{d} t)_{H}$ is the rate of change in larvae in the lake as a result of entrainment at the power plant. The rate of loss from the population equals the rate of accumulation at the power plant, $(\mathrm{d} L / \mathrm{d} t)_{H}=-\mathrm{d} H / \mathrm{d} t$, and

$$
\frac{\mathrm{d} H}{\mathrm{~d} t}=-(1-\phi) \frac{E U B}{2}\left(\frac{\mathrm{d} B}{\mathrm{~d} t}\right)_{H} .
$$

Substitution from Equation (9) on the left side gives

$$
h Q L=-(\mathrm{l}-\phi) \frac{E U B}{2}\left(\frac{\mathrm{d} B}{\mathrm{~d} t}\right)_{H},
$$


but $L=(1-\phi) G$ and $G=(E U B / 2) \cdot B$, so,

$$
\begin{aligned}
& h Q(1-\phi)\left(\frac{E U B}{2}\right) B \\
& \quad=-(1-\phi)\left(\frac{E U B}{2}\right)\left(\frac{\mathrm{d} B}{\mathrm{~d} t}\right)_{H},
\end{aligned}
$$

and cancellation of similar terms gives

$$
\left(\frac{\mathrm{d} B}{\mathrm{~d} t}\right)_{H}=-h Q B .
$$

This equation is applied to each power plant and the resulting equations are summed to give Equation (11). 